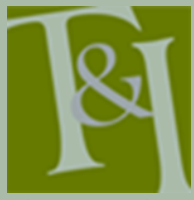

The International Journal for Translation \& Interpreting Research trans-int.org

\title{
Conveying medication prescriptions in American Sign Language: Use of emphasis in translations by interpreters and deaf physicians
}

\author{
Brenda Nicodemus \\ Gallaudet University, USA \\ brenda.nicodemus@gallaudet.edu \\ Laurie Swabey \\ St. Catherine University, USA \\ laswabey@stkate.edu
}

\section{Christopher Moreland}

The University of Texas Health Science Center-San Antonio, USA

cjmoreland@gmail.com

DOI: ti.106201.2014.a01

\begin{abstract}
In this study we examine linguistic features produced by interpreters and deaf bilingual physicians when translating medication instructions from English into American Sign Language (ASL). In the U.S. healthcare system, signed language interpreters are frequently called upon to facilitate communication between deaf individuals who use ASL and their non-signing physicians. A small but growing number of deaf individuals are now pursuing medical training, creating a situation in which deaf patients can communicate in ASL with their healthcare providers. Numerous practical and perceptual barriers affect patients' medication intake behaviors, including comprehension, memory of instructions, and language differences between physicians and patients. Research indicates that language concordance increases patients' compliance to prescription treatment. It follows that direct communication in ASL between deaf patients and deaf physicians will positively impact treatment compliance of patients and may result in better recall of medical instructions. We examined the linguistic features used in English to ASL translations of two medication directions as produced by experienced ASL-English interpreters $(n=3)$ and deaf bilingual physicians $(n=3)$. Results showed the absence of a standard approach for translating medication directions into ASL; however, both groups incorporated the same linguistic devices to promote emphasis within the translation, including repetition, emphatic lexical signs, and prosodic markers, presumably to promote recall of key concepts by deaf patients. Lexical variability in the translations is discussed, as well as information gaps between the ASL and English versions of the medication instructions. The results hold implications for healthcare professionals, interpreters, and interpreter educators for building effective communication for deaf patients.
\end{abstract}

Keywords: healthcare, prescriptions, interpreters, physicians, deaf, American Sign Language, repetition, modals, prosody, emphasis 
In the United States, deaf patients who use American Sign Language (ASL) typically communicate with their non-signing healthcare providers in one of two ways: in signed language (through an interpreter) or in English (by writing notes, lipreading, speaking, or a combination of these approaches).

The healthcare outcomes for deaf patients who use these different communication methods have not been thoroughly examined. However, deaf patients are frequently dissatisfied with communication in healthcare settings with non-signing providers (Harmer, 1999; Steinberg, Barnett, Meador, Wiggins, \& Zazove, 2006; Steinberg, Wiggins, Barmada, \& Sullivan, 2002; Ubido, 2002; Witte \& Kuzel, 2000). Further, deaf patients report a variety of issues in accessing healthcare services and, notably, express concerns with medication safety posed by inadequate communication (Iezzoni, O'Day, Killeen, \& Harker, 2004).

A critical issue in healthcare is compliance with prescription and treatment protocols (Alemanni, Touzin, Bussières, Descoteaux, \& Lemay, 2010; Cooper et al., 2009; Linn et al., 2012). Although providing medical instructions in ASL has positive results for deaf patients (MacKinney et al., 1995), it is not a panacea for communication problems, since instructions may be delivered with varying degrees of effectiveness in any language.

Studies have shown that the communication characteristics of some physicians appear to be more successful than others in achieving higher compliance among their patients (Sencan, Wertheimer, \& Levine, 2011). Thus, investigations are needed to better understand how to deliver healthcare instructions effectively in ASL, with specific attention to the linguistic devices that support deaf patients' comprehension and recall of medication instructions.

In this study, we begin the process by examining common medication instructions as translated from English into ASL by two groups: deaf bilingual physicians and experienced ASL-English interpreters. We investigate the linguistic features used when rendering medication instructions in ASL, and discuss features that may promote deaf patients' comprehension. Specifically we sought to learn if participants emphasized key concepts throughout their renditions and, if so, to identify the linguistic features that served as emphatic markers

The importance of effective doctor-patient communication as a key component in healthcare has been well documented (Cicourel, 1981; Davidson, 2001; Ha, Anat, \& Longnecker, 2010). Effective physician-patient communication has been linked to patient satisfaction and positive health outcomes (Betancourt, Carrillo, \& Green, 1999). Critically, patients who experience effective communication with their doctor are more likely to comply with the prescribed plan of treatment (Harmon, Lefante, \& KrouselWood, 2006; Sencan et al., 2011). Compliance is a complex health behavior determined by a variety of socioeconomic, individual, familial, and cultural factors.

Although studied extensively, non-compliance to prescribed treatment plans is a pervasive issue in the maintenance of public health worldwide (Sabaté, 2003; Zolnierek \& Dimatteo, 2009). Not adhering to prescription regimes has been directly tied to poor treatment outcomes for patients with a variety of illnesses, both chronic and acute. Non-compliance to medication plans carries societal implications as well. Patients with poor compliance may be unable to work or engage in family or community activities, thus negatively impacting their quality of life. Further, non-compliance results in a higher number of urgent care visits, hospitalizations, and other increases in costs related to treatment (Bond \& Haussar, 1991; Svarstad, Shireman, \& Sweeney, 2001). Disease management has also been cited as being negatively impacted by non-compliance. 
No matter the demonstrated efficacy of a treatment plan, without compliance, the benefit of the treatment will not be realized. It has been estimated that short-term medication therapies have a compliance rate between $70-80 \%$, while long-term medication therapies have a compliance rate between 40-50\% (Horne, Parham, Driscoll, \& Robinson, 2009).

A variety of types of non-compliance have been reported, including taking an incorrect dose of medication, taking medication at the wrong times, increasing or decreasing the frequency of doses, and stopping the treatment prematurely (Donovan \& Blake, 1992). Further, studies have indicated that adherence to medical therapy varies with the type of illness, with different compliance rates found for: bronchial asthma (Sabaté, 2003), hypertension (Monane et al., 1996), type 2 diabetes (Rubin, 2005), and inflammatory bowel disease (Horne et al., 2009).

These figures are of special concern for the healthcare of the deaf population since hypertension and diabetes occur more often in deaf adults than in their hearing peers (Hedding \& Kaufman, 2012).

Effective communication of healthcare instructions may enhance retention of information by patients. This is important since memory barriers have been identified as one of the critical factors influencing noncompliance of treatment plans (Bradshaw, Ley, Kincey, \& Bradshaw, 1975; Linn et al., 2012). Cushing and Metcalfe (2007) found that patients could remember only about $60 \%$ of what they had been told in the healthcare setting, an outcome that may be further taxed by stress, anxiety, and aging (Kessels, 2003). Individuals with limited English proficiency also are at higher risk in comprehending and remembering healthcare instructions (Jacobs et al., 2001). Since memory plays a critical role in the treatment compliance, communicating in a way that supports recall is critical when describing medication prescriptions or giving treatment instructions. Studies show that when healthcare providers emphasize key information in their instructions, patients perceive it to be important and their compliance to the treatment plan is increased (Ley, 1966; Ley, Bradshaw, \& Kincey, 1971).

With patients and physicians who use spoken languages, several communication strategies have been found to be instrumental in reducing memory barriers. Recall-promoting techniques include emphasizing key concepts, repeating information, summarizing, categorizing, structuring, providing written information, using cartoons or pictures, checking with patients for understanding, and avoiding technical jargon (Linn et al., 2012). These communication strategies are available when delivering prescription instructions into ASL, but to date, there has not been an examination of whether, or how, these strategies are employed in ASL healthcare discourse.

Other factors that increase compliance with medication regimes include a supportive, respectful patient-prescriber relationship (Lawson, Lyne, Harvey, \& Bundy, 2005), a level of health literacy that allows patients to read and understand drug labels (Butterworth, Banfield, Iqbal, \& Cooper, 2004), sufficient knowledge about the disease and treatment (including why medication may still be needed even after symptoms have disappeared (Bender \& Bender, 2005), and high levels of concordance between patient and doctor (Kerse et al., 2004). These factors can be significant; for example, patients reporting high levels of concordance with their doctors were one-third more likely to adhere to medication therapy prescribed during the appointment (Kerse et al., 2004).

Additional complexity occurs when the patient is deaf and uses American Sign Language and the physician is a hearing, non-signing individual. The Deaf community is a linguistic minority in North America; it has been estimated that there are at least 750,000 Americans and Canadians who are deaf and use ASL as their primary language (Canadian Association 
of the Deaf, 2012; Mitchell, 2004; Mitchell, Young, Bachleda, \& Karchmer, 2006).

Deaf individuals are surrounded by English in their daily lives, and therefore frequently communicate with other members of society in English by writing. However, most members of the Deaf community use ASL as their preferred means of communication with other people who know ASL.

ASL is articulated with the hands, face, and body and is perceived visually (or tactilely by deaf-blind individuals). Since ASL is expressed and perceived in a modality that is different from spoken languages (i.e., visualmanual vs. oral-aural), its linguistic features must be taken into account when examining healthcare discourse. A closed set of handshapes, locations, and movements constitute the sign lexicon of ASL. These are combined in rule-governed ways to comprise ASL syntactic structure.

Further, signed languages use prosody, non-segmental structures that indicate prominence and grouping of linguistic units (Shattuck-Hufnagel \& Turk, 1996). For example, specific facial articulations linguistically mark distinct types of syntactic structures (Baker \& Cokely, 1980), delineate phrasal constituents (Sandler, 1999), and perform adverbial and adjectival functions (Wilbur, 2000). In addition, lengthening (holding) of signs can signal important information or denote boundary markers in discourse (Miller, 1996; Nicodemus, 2009; Sandler, 1999).

The visual, three-dimensional modality of signed languages allows for expression of a wide range of conceptual structures, such as object and human actions, movements, locations, and shapes (see Sandler \& LilloMartin, 2006, for a review of linguistic structures of signed languages).

Language access in healthcare settings is essential. It is widely acknowledged that the language one uses should not be a factor in the health or mortality of an individual (Youdelman, 2008). However, health disparities between deaf people and people who can hear have not abated, even with legislation and increased access to interpreting services, including access through video technology (Barnett, 2002; Steinberg et al., 2006; Steinberg et al., 2002; Zazove et al., 1993).

Although federal legislation mandating communication access for deaf patients in healthcare settings in the U.S. was initially passed in 1973 (Section 504 of the Rehabilitation Act), implementation of that law and subsequent laws (e.g., Americans with Disabilities Act of 1990) have taken considerable time (Swabey \& Nicodemus, 2011). Physicians still report not using interpreters (Scheier, 2009), and deaf people report frustration, fear, and anxiety in accessing the healthcare system (Reeves \& Kokoruwe, 2005).

Fear of not being understood is a major concern for deaf people when visiting a doctor (Steinberg et al., 2006), and Scheier (2009) posits that the fear of receiving wrong medication or not understanding medication directions causes anxiety for deaf patients. In interviews, deaf and hard-ofhearing patients reported not understanding medication dosages, including side effects, as well as other treatment instructions (Iezzoni et al., 2004). Deaf people are less likely to visit a physician than their hearing counterparts (Barnett \& Franks, 2002) and have less health knowledge than people who can hear, regardless of their education level (Pollard \& Barnett, 2009;

Margellos H,, Hedding T., \& Miller L., 2004; Steinberg et al., 2002).

It has been estimated that deaf adults in the U.S. have a level of knowledge about medical terminology similar to that of non-English speaking immigrants to the U.S. (Steinberg et al., 2002). Hedding and Kaufmann (2012) suggest that communication barriers in the healthcare system and low health literacy are likely the main factors that account for poor health status of people who are deaf.

In a national survey of deaf people in the U.S., respondents identified healthcare as the most important setting in which to have interpreting 
services and, notably, also identified healthcare as the most difficult setting in which to obtain interpreting services (National Interpreter Education Center, 2009). Other studies corroborate this finding, with deaf individuals repeatedly reporting certified, experienced healthcare interpreters were not often available (Ebert \& Heckerling, 1995; Steinberg et al., 2006).

Positive experiences reported by deaf patients in healthcare settings included the use of ASL by healthcare providers, use of competent interpreting services, and the practice by providers (hearing or deaf) of taking sufficient time to clearly communicate, including the use visual aids as needed (Iezzoni et al., 2004). These positive experiences may be supported by several encouraging trends in healthcare services. One of the most important shifts is the small but growing number of deaf, ASL-English bilingual healthcare providers who are able to provide language concordant patient-provider communication (McKee, Barnett, Block, \& Pearson, 2011; Moreland, Latimore, Sen, Arato, \& Zazove, 2013).

Despite the legislative mandates for interpreters and increased demand by deaf patients for qualified healthcare interpreters, the need for qualified, certified practitioners who are trained to interpret between ASL and English in healthcare exceeds the supply. Interpreting practitioners have identified healthcare interpreting (medical and mental health) as the setting where training is the most urgently (National Interpreter Education Center, 2012).

Across the U.S., some states have legislation regarding the qualifications (e.g. certification, credentials, coursework) of healthcare interpreters, but most do not. It is not unusual for freelance interpreters with no specific education or training in healthcare settings to interpret in healthcare clinics (CATIE, 2007).

Unlike legal and educational interpreting, the national organization of signed language interpreters in the U.S., the Registry of Interpreters for the Deaf, does not currently offer a specialized certification or credential for healthcare interpreting, nor does it recommend specific educational coursework for this specialty. Fortunately, there is a small but growing body of research that identifies the complex and multidimensional aspects of ASL-English healthcare interpreting (Dean \& Pollard, 2011; Olson \& Swabey, 2013; Swabey, Nicodemus \& Moreland, in press).

While many studies have included various demographic factors that may impact compliance - including age, gender, ethnicity, education, and marital status (Jin, 2008) - no linguistic analyses have been conducted to date on healthcare communication with deaf patients who use ASL. In this study, we sought to identify the ASL linguistic features used by participants who were familiar with deaf patients and to examine if these features adhered to language recommendations made for hearing patients. We did so by examining ASL translations of medication treatment instructions produced by three ASL-English interpreters and three deaf bilingual physicians.

We begin the process by examining common medication instructions as translated from English into ASL by two groups: deaf bilingual physicians and experienced ASL-English interpreters. We investigate the linguistic features used when rendering medication instructions in ASL, and discuss features that may promote deaf patients' comprehension. Specifically we sought to learn if participants emphasized key concepts throughout their renditions and, if so, to identify the linguistic features that served as emphatic markers. 


\section{Method}

\section{Participants}

Two groups participated in this study.

The first participant group was composed of three deaf bilingual physicians with experience in treating deaf patients. These physicians were all fluent users of American Sign Language and regarded ASL as one of their primary languages. Two of the physicians were male.

The second participant group was composed of three ASL-English interpreters, each of whom had 22 or more years of professional interpreting experience and were recognized for their expertise in healthcare interpreting.

The interpreters all held national certification from the Registry of Interpreters for the Deaf and had completed bachelor's degrees or higher. All three had learned ASL as adults and reported that English was their native language. All three were female.

\section{Materials and Task}

The stimuli for this study were developed in consultation with a deaf physician who examined a broad sampling of medical questions and prescription directions and made recommendations for the final subset of questions and statements shown to the participants.

Three of the statements were medication directions. In this paper, we provide analysis of only two of these medication directives. The third statement was eliminated from analysis because, after consultation with other healthcare providers, we determined that the statement provided incomplete prescription instructions (see Appendix A for the complete list of questions and statements). The two medication statements analyzed in this paper are:

1) "Take one teaspoon three times a day for ten days. You should finish this medicine even if your symptoms disappear."

2) "Take this liquid medication four times a day-once after every meal and once before bedtime."

The physicians and interpreters had similar, but not identical, tasks to perform.

The physicians were individually given instructions in ASL by one of the researchers, a deaf bilingual physician. The questions and statements were presented individually in written English on 81/2 $\times 11$ papers placed face down in front of the physician. The order of presentation was the same for all of the participants (see Appendix A).

Each physician was instructed to turn over a paper one at a time, review the question or statement, and translate its meaning from English into ASL. The researchers and a professional videographer (to record the participant's translations) were present in the room while the translations were performed.

The three participating interpreters were also presented the same eight questions and statements individually, but in a slightly different format. On a laptop computer, the interpreters viewed a video-recorded simulation of a doctor (performed by an actor) who asked each question and statement separately in spoken English. One small difference in the spoken English version occurred in statement \#1 (listed above). In this statement, the actor concluded by saying, "Alright?" which was not in the print version shown to the physicians.

The interpreters were instructed to interpret the questions and statements consecutively, that is, to provide an ASL translation after hearing the entirety of each statement. The two hearing researchers were in the room with each interpreter; no one else was present. One of the researchers provided instructions in English while the other researcher video-recorded the translations. 
The physicians and interpreters were recruited by the researchers and video-recorded at four separate locations in the North, Southwest, Midwest, and Eastern regions of the U.S. Before beginning the task, each participant was informed that the study was being conducted to examine ASL translations of typical medical questions and instructions, specifically to learn more about the linguistic devices used in the translations.

The participants were given the opportunity to ask questions at any point during the study. Each participant was provided with an identical patient profile (i.e., an adult deaf patient with a high school education who uses ASL) and instructed to create a translation to match the needs of the patient profile. No time or length constraints were imposed for translating the statements.

\section{Transcription and Analysis}

The video data was transcribed separately by three individuals, a deaf native signer with over 15 years of signed language research experience and two hearing doctoral students in an interpretation program. Standard transcription techniques were used, including the following representation of fingerspelling (e.g., T-E-A-S-P-O-O-N), gesture (e.g., gesture: 'opening- $a$ bottle'), and classifier constructions (e.g., CL:C, indicating an ASL classifier with a $\mathrm{C}$ handshape). The ${ }^{*}$ symbol was used to indicate prosodic emphasis in the signed productions.

By convention, the ASL signs were glossed in English capital letters. The transcriptions were compiled in an Excel spreadsheet and were reviewed for accuracy by the researchers. For analysis, we reviewed both the transcriptions and the video-recorded translations. The transcribed and video data were examined for frequently used linguistic features within the translations, with a focus on features that served to create emphasis because they may support memory.

Here, we first present each medication statement in English and discuss potential challenges in creating an ASL translation of the material. We then provide a linguistic analysis of the ASL translations, with a focus on the use of emphatic markers, including repetition, lexical selections, and prosody. In total, we provide an analysis of 12 translations, two statements translated by six participants. In addition, we offer two full sample transcriptions of the data, one from a physician and one from an interpreter.

\section{Potential Challenges in Translating the Medication Prescription Statements}

(1): "Take one teaspoon three times a day for ten days. You should finish this medicine even if your symptoms disappear". This prescription directive contains information that is critical to a patient's treatment but poses challenges to translate into ASL. The first sentence ("Take one teaspoon three times a day for ten days.") contains three numbers, each linked to a different noun ("one teaspoon," "three times," "ten days"). Three numbers and referents in one short sentence create a situation in which the information could be inverted during translation.

Even if produced correctly, the density of the sentence may tax the memory of the patient. The phrase "take one teaspoon" may best be produced in ASL using depiction, a set of linguistic devices that employ the body and surrounding space to represent entities (Dudis, 2007, 2004), but the use of depiction is non-obligatory in ASL and depends upon the discretion of the participant.

In addition, the medication instructions are given in the form of a directive statement. In ASL, emphatic directives are frequently conveyed through the use of a modal, a lexical item that conveys the conceptual domain of necessity and possibility (Shaffer, 2004), but may also include 
adjectival markers, prosodic cues, or a combination of both.

Finally, the phrase "three times a day" is generally understood to mean that the medicine should be taken with food, typically at mealtimes, or at a prescribed interval over the course of the day. However, the statement in English does not specify this information, and the participant must decide whether to explicate this information or not.

The second part of the prescription instruction is critical in that it states the medication must be taken in its entirety, even if the patient is asymptomatic. The statement may pose challenges for translation because the lexical item "symptoms" does not have a standard correspondent in ASL. To convey the meaning then, the participant may choose to translate the term by providing examples of symptom types. In this case, however, the symptoms are unknown, so the signer must devise an alternative way to express the concept.

The phrase "symptoms disappear" may also be difficult to translate. "Disappear" has a specific meaning in this context, and although there is an ASL citation form for DISAPPEAR, the participant must determine if it is appropriate for this translation. Although not the focus of this paper, it is interesting to note that five of the participants reformulated the phrase in their ASL translations; that is, to convey "symptoms disappear," three participants used the ASL phrase FEEL BETTER and two participants used the "thumbs up" gesture.

(2): "Take this liquid medication four times a day-once after every meal and once before bedtime (alright?)".

Compared with the first medication instruction statement described above, this medication directive poses fewer challenges to translate into ASL. The instructions are straightforward and provide two details that can easily be specified in ASL: the form of the medication (liquid) and that the medication is to be taken after meals and before bed.

Although ASL does not have a generic sign for "meal," there are standard and non-standard variants for expressing "breakfast," "lunch," and "dinner." These variations were observed in this data set. Given that the participants' translations were produced in a consecutive format, the time needed to specify each meal did not particularly pose a challenge. However, this sentence would be more challenging if interpreted in a simultaneous format or under other time constraints.

ASL does not have a standard lexical correspondent for "liquid;" however, the verb "take" can be used to specify the form of the medicine. Because "liquid" is included in the English sentence, a participant can reduce the number of choices for translating the verb "take" to "take by spoon" or "take in a small dosage cup." Both of these options were observed in this data set.

Had the physician said, "Take this medication" (without specifying "liquid"), the translation might have required more cognitive effort, as a typical ASL verb choice to convey taking medicine specifies the way the medication is to be administered (e.g., via drops, injection, inhaler, pill, liquid from a cup, liquid from a spoon, patch) (Swabey, Nicodemus \& Moreland, in press).

Given the importance of patients' understanding instructions for treatment compliance, we were interested in learning if the deaf physicians and interpreters used emphasis in their ASL translations, and, if so, what linguistic devices they used to highlight information. In the following sections, we examine these linguistic devices, as well as the lexical choices used by the deaf physicians and interpreters in their ASL translations of the medication prescription statements. 


\section{Results}

The data revealed that, although the translations were distinctly different from one another, all six participants employed the same three linguistic devices-repetition, emphatic lexical items (modals), and prosody-to emphasize specific content in the statements. The presence of each feature in the translations is described in detail below.

\section{Repetition}

The deaf physicians (DP) and interpreter (INT) participants used repetition to emphasize the numbers in their ASL versions of the medication instructions "Take one teaspoon three times a day for ten days." The ASL number signs were frequently repeated two or three times, and in one instance, the number sign for THREE was produced a total of four times (see Table 1).

Table 1: Number of Repetitions of Each ASL Number Sign Used in the Translations of "Take one teaspoon three times a day for ten days."

\begin{tabular}{lccc}
\hline Participant & $\begin{array}{c}\text { ASL sign } \\
\text { "ONE" }\end{array}$ & $\begin{array}{c}\text { ASL sign } \\
\text { "TWO" }\end{array}$ & $\begin{array}{c}\text { ASL sign } \\
\text { "THREE" }\end{array}$ \\
\hline$D P 1$ & 2 & 4 & 2 \\
\hline$D P 2$ & $0^{*}$ & 1 & 3 \\
\hline$D P 3$ & $0^{*}$ & 1 & 2 \\
\hline$I N T 1$ & 2 & 1 & 2 \\
\hline INT2 & $0^{*}$ & 2 & 2 \\
\hline INT3 & 2 & 1 & 2
\end{tabular}

* Information conveyed by depiction of taking medication, rather than by a number sign.

Repetition was also employed in translations of the second part of this medication directive "You should finish this medicine even if your symptoms disappear." All six participants used an ASL phrase to convey this information and repeated the phrase two to three times to convey that the medicine must continue to be taken even if the patient is asymptomatic (see Table 2).

Table 2: ASL Lexical Choices and Number of Repetitions for the Concept of "Finish this medicine."

\begin{tabular}{llc}
\hline Participant & \multicolumn{1}{c}{$\begin{array}{c}\text { ASL } \\
\text { Translation }\end{array}$} & $\begin{array}{c}\text { Number of } \\
\text { Repetitions }\end{array}$ \\
\hline$D P 1$ & ALL-GONE & 3 \\
\hline$D P 2$ & USE-UP & 3 \\
\hline DP3 & END & 2 \\
\hline$I N T 1$ & ALL-GONE & 2 \\
\hline INT2 & CONTINUE & 2 \\
\hline INT3 & CONTINUE & 2 \\
\hline
\end{tabular}


The second medication directive "Take this liquid medication four times a day-once after every meal and once before bedtime" contains only one numeral in English. Nonetheless, five participants repeated the ASL number sign FOUR, two or three times (see Table 3). It is interesting to note that five of the participants also used an ASL listing convention, commonly glossed as LIST-FOUR. To demonstrate a list of four things, the number sign FOUR is produced with the non-dominant hand while the dominant hand points to the first finger and then is used to produce the corresponding item (e.g., breakfast). Pointing to the rest of the fingers continues in order to express the next corresponding items (e.g., lunch, dinner or before bed). This listing process serves to emphasize the information about taking four dosages daily.

Finally, five out of six participants repeated the consumption or "taking" of medication in their renditions, between 5-10 times (see Table 3). Three participants depicted the medicine being consumed by showing how the patient would drink it. This depiction of drinking medicine was repeated five times by DP3, six times by INT3, and ten times by INT1. One participant (INT2) depicted the liquid medicine as being consumed from a spoon a total of six times in her rendition. DP1 used the sign TAKE-PILL and repeated it five times.

A common approach used by the participants was for the consumption of medication to be depicted for all four doses throughout the day and also once or twice to introduce the dosage regime (see Table 3).

Within and across the participants' translations, repetition was used frequently; however, it is interesting to note that there was variation regarding what information was repeated, how it was repeated (e.g., lexical signs, depiction), and the number of repetitions.

Table 3: Repetition of the Number Sign "FOUR" and Concept "TAKEMEDICINE" (Either via a Sign or Depiction) for the Directive "Take this liquid medication four times a day-once after every meal and once before bedtime."

\begin{tabular}{lcrl}
\hline $\begin{array}{c}\text { Participant } \\
\text { "FOUR" (times) }\end{array}$ & $\begin{array}{c}\text { Repetition of } \\
\text { "FAKE-MEDICINE" }\end{array}$ \\
\hline$D P 1$ & 3 & 5 & (sign) \\
\hline$D P 2$ & 2 & 1 & (depiction) \\
\hline$D P 3$ & 3 & 5 & (depiction) \\
\hline & & & \\
\hline INT1 & 1 & 10 & (depiction) \\
\hline INT2 & 3 & 6 & (depiction) \\
\hline INT3 & 2 & 6 & (depiction) \\
\hline
\end{tabular}

\section{Lexical and Modal Emphasis}

Five out of the six participants added ASL signs or phrases in their translations that emphasized the importance of adhering to the dosage regimen (see Table 4).

In the first medication directive, a modal ("should") is present in the English version ("You should finish this medicine even if your symptoms disappear."), which corresponds to the emphasis created in the ASL translations. 
Table 4: ASL Modals and Other Lexical Items Used by Participants in Their Translations of the Directive "Take one teaspoon three times a day for ten days. You should finish this medicine even if your symptoms disappear."

\begin{tabular}{ll}
\hline Participant & \multicolumn{1}{c}{$\begin{array}{c}\text { ASL Modals and } \\
\text { Lexical Items }\end{array}$} \\
\hline$D P 1$ & MUST TAKE-PILL \\
\hline$D P 2$ & $\begin{array}{l}\text { MEDICINE } \\
\text { IMPORTANT } \\
\text { IMPORTANT } \\
\text { IMPORTANT } \\
\text { IMPORTANT }\end{array}$ \\
\hline DP3 & MUST \\
\hline INT1 & MUST \\
\hline INT2 & IMPORTANT \\
\hline INT3 & NO EXCUSE \\
\hline
\end{tabular}

In contrast, for the second medication directive, "Take this liquid medication four times a day-once after every meal and once before bedtime," only one participant (DP 2) added information about the importance of following a regime. These additions by DP 2 include IMPORTANT ( 3 times) and MUST ( 2 times). Unlike the first medication directive, the second one did not include a modal in the original English statement.

\section{Prosody}

The data revealed that the participants used ASL prosodic markers to emphasize specific information in the prescription instructions. These markers included: tense (vs. lax) signed production, emphatic head nods, shifting eye gaze (toward sign or away from listener), and pausing after signs.

In the medication instructions "Take one teaspoon three times a day for ten days. You should finish this medicine even if your symptoms disappear," prosodic markers emphasized the imperative nature of the statement, typically on the modal (MUST), but also on related lexical items (REQUIRE, IMPORTANT, CONTINUE) (see Table 5).

\section{Challenges in Translating}

On the surface, the second medication directive poses relatively few challenges. There are standard ASL lexical correspondents or strategies to express the concepts in this directive, reducing the amount of contextualization required.

Despite this, it is interesting to note that several errors were still found in the participants' ASL translations that could cause confusion for patients, both related to the type of medication (PILL instead of LIQUID) and the timing of the medication ("before or with meals" instead of "after meals"). Four of the six participants rendered the directions incorrectly by repeatedly stating that the medication should be taken "before breakfast, before lunch, and before dinner." 
Table 5: Emphasis Conveyed via ASL Prosodic Markers in the Translation of the Directive "Take one teaspoon three times a day for ten days. You should finish this medicine even if your symptoms disappear."

\begin{tabular}{lcccc}
\hline $\begin{array}{l}\text { Participant } \\
\text { and Sign }\end{array}$ & $\begin{array}{c}\text { Tense } \\
\text { Production }\end{array}$ & $\begin{array}{c}\text { Emphatic } \\
\text { Head Nod }\end{array}$ & $\begin{array}{c}\text { Eye Gaze } \\
\text { Shift }\end{array}$ & $\begin{array}{c}\text { Pausing } \\
\text { after Sign }\end{array}$ \\
\hline $\begin{array}{l}\text { DP1 } \\
\text { "REQUIRE" }\end{array}$ & $\mathrm{X}$ & $\mathrm{X}$ & - & $\mathrm{X}$ \\
\hline $\begin{array}{l}\text { DP2 } \\
\text { "IMPORTANT" }\end{array}$ & - & $\mathrm{X}$ & - & $\mathrm{X}$ \\
\hline $\begin{array}{l}\text { DP3 } \\
\text { "MUST" }\end{array}$ & $\mathrm{X}$ & $\mathrm{X}$ & $\mathrm{X}$ & - \\
\hline $\begin{array}{l}\text { INT1 } \\
\text { "IMPORTANT" }\end{array}$ & $\mathrm{X}$ & $\mathrm{X}$ & - & $\mathrm{X}$ \\
\hline $\begin{array}{l}\text { INT2 } \\
\text { "CONTINUE }\end{array}$ & $\mathrm{X}$ & - & $\mathrm{X}$ & - \\
\hline $\begin{array}{l}\text { INT3 } \\
\text { "MUST" }\end{array}$ & $\mathrm{X}$ & $\mathrm{X}$ & $\mathrm{X}$ & - \\
\hline Note: "X" denotes use of prosodic marker. & & & \\
\hline
\end{tabular}

We can only hypothesize why this major error occurred in this sample. One possibility is that the participants remembered the temporal aspect stated at the end of the directive-"before bedtime"-and then incorrectly applied "before" to the other dosages during the day.

Another possibility is that memory was influenced by the format in which the directives were presented. Three of the renditions with this error were made by participants who read the directive and one was from a participant who heard the directive. In addition, one participant incorrectly rendered the form of the medication as a pill, repeatedly signing to "take a pill" before meals and before bedtime.

\section{Data Samples}

In this section, we offer two data samples from the study, one translation produced by a deaf bilingual physician (DP1) and one produced by an interpreter (INT1). These samples illustrate the use of the linguistic devices described in this paper. Both translations are of the directive "Take one teaspoon three times a day for ten days. You should finish this medicine even if your symptoms disappear."

Sample 1, produced by one of the deaf bilingual physicians, exhibits all three linguistic features that emphasize key concepts. First, incidents of repetition are shown in bold in the sample. The sign ONE is produced two times (line 3), the sign THREE is produced three times (lines 4, 8, 9), and the sign TEN is produced two times (lines 10,11). Emphatic lexical items (including a modal) are underlined in the sample and are found in lines 9 (UNDERSTAND), 11 (MUST), and 14 (be-careful). Finally, the use of prosody for emphasis (indicated by an * symbol) may be found in lines 5,8 , 11 , and 14.

\footnotetext{
${ }^{1}$ To assist with comprehension, we have included a back translation in English under the transcription.
} 
Sample 1: A Deaf Physician's (DP1) ASL Translation of the Directive "Take one teaspoon three times a day for ten days. You should finish this medicine even if your symptoms disappear."

1) CL: (C-handshape) -'bottle', gesture: 'take-one-teaspoon-out' (nod)/ 'Take one teaspoon from the bottle.'

2) THAT INCLUDE gesture:'take-one-teaspoon-out' O-R (neg head shake) DEPEND MEDICINE gesture: 'twist-cap' (nod)/ 'It could be either by teaspoon or by the cap of the medicine.'

3) YOU, gesture: 'twist-cap', gesture: 'hold-cap', gesture: 'pour-intocap' THAT ONE gesture: 'point- to-cap' ONE gesture: 'point-tocap' (nod)//

'Open the cap and take only one capful.'

4) gesture: 'hold-cap', gesture: 'point-to-cap' gesture: 'drink-from-cap' THREE TIME EVERYDAY D-A-Y YOU (nod) 'Take it three times a day.'

5) UNDERSTAND* MEAN gesture: 'drink-from-cap' MORNING 'By that I mean, take one capful in the morning.'

6) gesture: 'pour-into-cap' AGAIN gesture: 'drink-from-cap' AFTERNOON 'Another in the afternoon,'

7) gesture: 'pour-into-cap' AGAIN gesture: 'drink-from-cap' NIGHT// 'And once again in the evening.'

8) THREE TIME EVERYDAY D-A-Y REQUIRE* (nodding). 'It's important that you take the medicine three times a day.'

9) UNDERSTAND* THREE TIME EVERYDAY D-A-Y// 'That's three times daily.'

10) gesture: 'subsequent' TEN DAY, gesture: 'subsequent' gesture: 'end-and-beginning' 'Take the medicine for ten full days."

11) YOU MUST* TAKE-PILL THREE TIME D-A-Y FOR TEN DAYII 'Take it three times a day for ten days.'

12) END ALL-GONE-IN-BOTTLE 'Until the medicine is entirely gone.'

13) YOU FEEL BETTER gesture: 'thumbs-up' BUT GO-AHEAD ALL-GONE-IN-BOTTLE 'You may feel better, but make sure you take the medicine until it is gone.'

14) YOU MISS ONE CAN INFECTION BECOME WORSE (nod) gesture: 'be-careful'* 'If you miss even one dose, the infection can worsen.'

15) YOU FEEL BETTER STILL ALL-GONE-IN-BOTTLE GONE (nod)//

'So even if you feel better, make sure you take the full dosage of medicine.'

Sample 2 is a transcription of an ASL translation produced by one of the interpreters for the same statement. Incidents of repetition are shown in bold in the sample and are found in lines 1 (ONE), 2 (TEN), and 4 (TEN). An emphatic lexical item (underlined) occurs in line 4 (IMPORTANT). Emphatic prosodic markers (indicated by $*$ ) are found in lines 3 and 4 . 


\section{Sample 2: An Interpreter's (INT1) Translation of the Directive "Take one teaspoon three times a day for ten days. You should finish this medicine even if your symptoms disappear."}

1) YOU ONE T-E-A-S-P-O-O-N gesture: 'take-from-spoon' ONE gesture: 'drink-from-small- vessel' (nodding) THREE TIME++ EVERY-DAY

'Take one teaspoon three times everyday.'

2) NOON AFTERNOON EVENING NOON AFTERNOON

EVENING CONTINUE TEN D-A-Y-S

'The medicine should be taken at noon, in the afternoon and in the evening for 10 days.'

3) YOU PROBLEM DISSOLVE FEEL BETTER gesture: 'payattention' STILL CONTINUE*

'Even if your symptoms disappear, you should still continue the course of your medicine.'

4) RUN-OUT TO TEN D-A-Y-S RUN-OUT FINISH IMPORTANT** (nodding)//

'It's important that you take the medicine for ten full days until it is completely gone.

\section{Discussion}

In this study we identified three linguistic devices--repetition, emphatic lexical signs, and prosodic markers--used in ASL translations of medication prescriptions by deaf bilingual physicians and experienced ASL-English interpreters.

These findings mirror results from studies of English healthcare discourse in which key concepts are emphasized and repetition is used by healthcare providers (Linn et al., 2012). Deaf patients may comprehend and retain information better through use of specific linguistic features in ASL; further, this knowledge can contribute to the education of ASL-English healthcare interpreters.

Angelelli (2006) has advocated for the development of skills in six areas for healthcare interpreters: cognitive processing, as well as interpersonal, linguistics, professional, setting-specific, and sociocultural knowledge. Dean and Pollard (2012) have written extensively about using the demand-control schema to structure experimental learning. Others (Major, Napier, \& Stubbe, 2012) describe using authentic healthcare interactions in discourse training for healthcare interpreters.

Bowen-Bailey (2012) provides specific guidance on developing online learning modules for healthcare interpreting using Vygotsky's framework, and Nicodemus, Swabey \& Witter-Merithew (2012) have reiterated the need for problem-based learning, case studies, and observation-supervision in the education of healthcare interpreters. Overall, the consensus in the literature is that the traditional teacher-centered model of instruction should be discarded in favor of a dynamic, collaborative, learning-centered model that involves observing and solving real-world challenges in the healthcare setting, including the linguistic challenges found in healthcare discourse.

Although there is a degree of agreement about educational approaches, there continues to be a need for studies that examine the interpreted interactions that occur between patients who use ASL and physicians who use English, along with specific curricula that address the full spectrum of competencies needed for healthcare interpreting. In the U.S. there is no accepted standard for the education of healthcare interpreters, and although the literature is growing, there is only a small body of evidence regarding the effectiveness of the education of ASL-English healthcare interpreters. 
In a revealing study of Spanish-English professional interpreters, number of hours of training, but not years of experience, were associated with a significantly lower number of errors (Flores, Abreu, Barone, Bachur, \& Lin, 2012). Similar studies for ASL-English interpreting are needed, as are investigations into the influence of quality of interpreter and physician communication on health outcomes for deaf patients (Steinberg et al., 2005). Only with such evidence are states or healthcare organizations likely to require a specific credential or degree for employment as an interpreter.

In this study, we have discussed the importance of compliance with medication therapies in regard to improving positive healthcare outcomes for all patients, as well as reviewing some specific challenges for deaf patients in accessing accurate medication information. To date, the crucial topic of accurately rendering information about medication protocols is barely addressed in the education of ASL-English interpreters.

Interpreters need to be aware of the linguistic features used by expert interpreters and deaf healthcare providers when attempting to convey medical information in the most effective manner. Anecdotally, ASLEnglish interpreters express that knowledge of healthcare terms, understanding of healthcare concepts, familiarity with healthcare systems, navigating boundaries, and ethical and professional decision-making are important knowledge and skill areas.

We propose a focus in interpreter education, not only on content (e.g., knowledge of the cardiovascular system, terms for cancer treatment), but also on the effective use of linguistic devices in ASL (e.g., repetition, lexicon, prosody) that may be used to accurately convey the urgency or emphasis expressed in the original message.

The results of this study are based on a small sample size. While the results would be more conclusive given a larger sample size, the number of deaf bilingual physicians is relatively small in the total physician population. In addition, because there is no specialized credential in healthcare interpreting for ASL-English interpreters, the selection of interpreter participants also posed a challenge.

Further, in addition to the patient profile given to the participants, an ideal approach would have been to provide video simulations of specific patients as well. Analysis of authentic healthcare interactions in ASL would also be useful in understanding the use of linguistic features. Despite these limitations, we argue it is critical to conduct empirical studies, both observational and experimental, on interpretations and translations of healthcare material.

Interpersonal healthcare communication is increasingly stressed in the training of healthcare providers. In addition, the inclusion of strategies for identifying and mediating barriers to compliance for medication intake has been recommended as an important component of provider education (Linn et al., 2012). Including information about the numerous strategies that providers use to enhance medication compliance (e.g., responding to emotional cues of the patient, encouraging patient participation, and seeking involvement in the decision-making practice) in interpreter curricula might also prove to be prudent, so that the goals of interpreters and healthcare providers can be more closely aligned.

Developing and teaching a range of standard translations from English into ASL for common medication prescriptions may be a useful step in training healthcare interpreters. Without question, interpretations must be modified depending upon linguistic, social, and cultural factors present in the situation, but there may be merit in creating sample ASL translations for interpreters to study and discuss with deaf patients. 
To this end, we support taking a community-based, participatory research approach, that is, a collaborative process between researchers and community partners, both deaf and hearing (Starr \& Graybill, 2012).

\section{Conclusion}

The findings of this linguistic analysis demonstrate the absence of a standard approach for translating medication prescriptions from English into American Sign Language by three deaf bilingual physicians and three expert ASL-English interpreters. Despite the variation, both groups incorporated the same three linguistic devices-repetition, emphatic lexical items, and prosody-into their translations, presumably to emphasize key concepts in the medication directives.

Given the widespread problem of medication compliance, especially among minority populations, it is surprising that prior studies have not described the ASL linguistic features used in healthcare interactions. This descriptive analysis of ASL renditions of typical medication instructions is a useful first step and may be used to inform the communication practices of both deaf bilingual physicians and ASL-English interpreters. The growing number of deaf healthcare professionals and increased emphasis on healthcare interpreters are encouraging developments, but much more information is needed about how to deliver healthcare information effectively in American Sign Language. Further investigation of deaf patients' comprehension of medication instructions given in ASL and their subsequent compliance is also needed.

Much work remains to be done, both in defining effective healthcare interpretation and infusing evidence-based studies into interpreter education programs. The growing number of deaf healthcare professionals and increased emphasis on healthcare interpreting are encouraging developments, but more information is needed about how to deliver healthcare information effectively in American Sign Language. Understanding the linguistic features used in ASL healthcare discourse is a critical first step in that pursuit.

\section{Acknowledgements:}

This study was supported by a research grant from the Registry of Interpreters for the Deaf awarded to Laurie Swabey and Brenda Nicodemus. We extend our thanks to the following individuals for their assistance with this project: Doug Bowen-Bailey, Vicki Everhart, Richard Laurion, Annette Miner, Lucinda O'Grady, Derek Roff, and Leandra Williams. We are especially grateful to Roberto Santiago for his significant contributions to the transcription and translation work necessary for this study. Finally, this study would not have been possible without the generous contributions of the physicians and interpreters, to whom we extend our sincere gratitude. 


\section{References}

Alemanni, J., Touzin, K., Bussières, J., Descoteaux, R., \& Lemay, M. (2010). An assessment of drug administration compliance in a university hospital centre. Journal of Evaluation in Clinical Practice, 16(5), 920-926.

Angelelli, C. (2006). Designing curriculum for healthcare interpreting education: A principles approach. In C. Roy (Ed.), New approaches to interpreter education (23-46). Washington, DC: Gallaudet University Press.

Baker, C., \& Cokely, D. (1980). American Sign Language: A teacher's resource text on grammar and culture. Silver Spring, MD: TJ Publishers.

Barnett, S. L. (2002). Communication with deaf and hard-of-hearing people: A guide for medical education. Academic Medicine, 77, 694-700.

Barnett, S., \& Franks, P. (2002). Healthcare utilization and adults who are deaf: Relationship with age at onset of deafness. Health Services Research, 37, 105-120.

Bender, B., \& Bender, S. (2005). Patient-identified barriers to asthma treatment adherence: Responses to interviews, focus groups, and questionnaires. Immunology and Allergy Clinics of North America, 25, 107-130.

Betancourt, J. R., Carrillo, J. E., \& Green, A. R. (1999). Hypertension in multicultural and minority populations: Linking communication to compliance. Current Hypertension Reports, 482-488.

Bond, W., \& Haussar, D. (1991). Detection methods and strategies for improving medication compliance. American Journal of Hospital Pharmacy, 48, 1978-1988.

Bowen-Bailey, D. (2012). Just what the doctor ordered? Online possibilities for healthcare interpreting education. In L. Swabey \& K. Malcolm (Eds.), In our hands: Educating healthcare interpreters (164-189). Washington, DC: Gallaudet University Press.

Bradshaw, P. W., Ley, P., Kincey, J. A., \& Bradshaw, J. (1975). Recall of medical advice: Comprehensibility and specificity. British Journal of Clinical Psychology, 14, 55-62.

Butterworth, J. R., Banfield, L. M., Iqbal, T. H., \& Cooper, B. T. (2004). Factors relating to compliance with a gluten-free diet in patients with coeliac disease: Comparison of white Caucasian and South Asian patients. Clinical Nutrition, 23(5), 1127-1134.

Canadian Association of the Deaf. (2012). Statistics on Deaf Canadians. Retrieved October 15, 2012, from http://www.cad.ca/statistics_on_deaf_canadians.php

CATIE Center, College of St. Catherine and NCIEC. (2007). "Medical interpreting focus groups: Results for the background and experience survey," http://www.medicalinterpreting.org/PDF/FocusGroupSurvey.pdf.

Cicourel, A. V. (1981). Language and the structure of belief in medical communication. Studia Linguistica, 35(1-2), 71-85.

Cooper, L. A., Cooper, D. A., Roter, D. L., Bone L. R., Larson, S. M., Miller, E. R., Barr, M. S., Carson, K. A., \& Levine, D. M. (2009). A randomized controlled trial of interventions to enhance patientphysician partnership, patient adherence and high blood pressure control among ethnic minorities and poor persons: Study protocol NCT00123045. Implementation Science, 4(7) 4-7.

Cushing, A., \& Metcalfe, R. (2007). Optimizing medicines management: From compliance to concordance. Therapeutics and Clinical Risk Management, 3(6), 1047-1058. 
Davidson, B. (2001). Questions in cross-linguistic medical encounters: The role of the hospital interpreter. Anthropological Quarterly, 74(4), 170178.

Dean, R., \& Pollard, R. (2011). Context-based ethical reasoning in interpreting: A demand-control schema perspective. Interpreter and Translator Trainer, 5(1), 155-182.

Donovan, J. L., \& Blake, D. R. (1992). Patient non-compliance: Deviance or reasoned decision-making? Social Science \& Medicine, 34(5), 507-513.

Dudis, P. G. (2004). Body partitioning and real-space blends. Cognitive Linguistics, 15(20), 223-238.

Dudis, P. (2007). Types of depiction in ASL. (Unpublished manuscript, Gallaudet University).

Ebert, D. A., \& Heckerling, P. S. (1995). Communication with deaf patients: Knowledge, beliefs, and practices of physicians. The Journal of American Medical Association, 273(3), 227-229.

Flores, G., Abreu, M., Barone, C. P., Bachur, R., \& Lin, H. (2012). Errors of medical interpretation and their potential their potential clinical consequences: A comparison of professional versus ad hoc versus no interpreters. Annals of Emergency Medicine, 60(5), 545-553.

Ha, J. F., Anat, D. S., \& Longnecker, N. (2010). Doctor-patient communication: A review. The Ochsner Journal, 10, 38-43.

Harmer, L. (1999). Health care delivery and deaf people: Practice, problems, and recommendations for change. Journal of Deaf Studies and Deaf Education, 4(2), 73-110.

Harmon, G., Lefante J., \& Krousel-Wood, M. (2006). Overcoming barriers: The role of providers in improving patient adherence to antihypertensive medications. Current Opinion in Cardiology, 21(4) 310-315.

Hedding, T., \& Kaufman, G. (2012). Health literacy and deafness: Implications for interpreter education. In L. Swabey \& K. Malcolm (Eds.), In our hands: Educating healthcare interpreters (164-189). Washington, DC: Gallaudet University Press.

Horne, R., Parham, R., Driscoll, R., \& Robinson, A. (2009). Patients' attitudes to medicines and adherence to maintenance treatment in inflammatory bowel disease. Inflammatory Bowel Disease, 15(6), 837844.

Iezzoni, L., O'Day, B., Killeen, M., \& Harker, H. (2004). Communicating about health care: Observations from persons who are deaf or hard of hearing. Annals of Internal Medicine, 140(5), 356-363.

Jacobs, E. A., Lauderdale, D. S., Meltzer, D., Shorey, J. M., Levinson, W., \& Thisted, R. A. (2001). Impact of interpreter services on delivery of health care to limited-English- proficient patients. Journal of General Internal Medicine, 16(7), 468-474.

Jin, J. (2008). Factors affecting therapeutic compliance: A review from the patient's perspective. Therapeutics and Clinical Risk Management, 4(1), 269-286.

Kerse, N., Buetow, S., Mainous, A., Young, G. Coster, G., \& Arroll, B. (2004). Physician-patient relationship and medication compliance: A primary care investigation. Annals of Family Medicine, 2(5), 455-461.

Kessels, R. P. C. (2003). Patients' memory for medical information. Journal of the Royal Society of Medicine, 96, 219-222.

Lawson, V., Lyne, P., Harvey, J., \& Bundy, C. (2005). Understanding why people with type 1 diabetes do not attend for specialist advice: A qualitative analysis of the views of people with insulin-dependent diabetes who do not attend diabetes clinic. Journal of Health Psychology, 10, 409-423.

Ley, P. (1966). What the patient forgets. Medical Opinion Review, 1, 71-73. 
Ley, P., Bradshaw, P. W., \& Kincey, J. A. (1971). Patients' compliance with medical advice. (First Annual Report, Unit for Research into DoctorPatient Communication).

Linn, A. J., van Weert, J. C. M., Schouten, B. C., Smit, E. G., van Bodegraven, A. A., \& van Dijk, L. (2012). Words that make pills easier to swallow: A communication typology to address practical and perceptual barriers to medication intake behavior. Patient Preference and Adherence, 6, 871-885.

MacKinney, T. G., Walters, D., Bird, G. O., \& Nattinger, A. B. (1995). Improvements in preventive care and communication for deaf patients. Journal of General Internal Medicine, 10(3), 133-137.

Major, G., Napier, J., \& Stubbe, M. (2012). "What happens truly, not textbook!": Using authentic interactions in discourse training for healthcare interpreters. In L. Swabey \& K. Malcolm (Eds.), In our hands: Educating healthcare interpreters (164-189). Washington, DC: Gallaudet University Press.

Margellos H,, Hedding T., \& Miller L. (2004). Improving Access to Health and Mental Health for Chicago's Deaf Community: A Survey of Deaf Adults. Chicago, Illinois: Sinai Health System and Advocate Health Care,

McKee, M. M., Barnett, S. L., Block, R. C., \& Pearson, A. P. (2011). Impact of communication on preventative services among deaf American Sign Language users. American Journal of Preventative Medicine, 41(1), 7579.

Miller, C. (1996). Phonologie de la langue des signes québécoise: Structure simultanée et axe temporel. (Unpublished doctoral dissertation, Université du Québéc, Montreal).

Mitchell, R. E. (2004, April 7). How many people use ASL? And other good questions without good answers. (Paper given at Gallaudet University). Retrieved October 15, 2012, from http://research.gallaudet.edu/Presentations/2004-04-07-1.pdf

Mitchell, R. E., Young, T. A., Bachleda, B., \& Karchmer, M. A. (2006). How many people use sign language in the United States? Why estimates need updating, Sign Language Studies, 6(3), 306-335.

Monane, M., Bohn, R., Gurwitz, J., Glynn R. J., Levin R., \& Avorn J. (1996). Compliance with antihypertensive therapy among elderly Medicaid enrollees: The roles of age, gender, and race. American Journal of Public Health, 86, 1805-1808.

Moreland, C. J., Latimore, D., Sen, A., Arato, N., \& Zazove, P. (2013). Deafness among physicians and trainees: A national survey. Academic Medicine, 88(2), 224-232.

National Interpreter Education Center. (2009). Phase two deaf consumer needs assessment: Final report. Retrieved from http://www.interpretereducation.org/wp-content/ uploads/2011/06/FinalPhaseIIDCReport.pdf

National Interpreter Education Center. (2012). Interpreter practitioner national needs assessment of 2012: Final report. Retrieved from http://www.interpretereducation.org/wp content/uploads/2013/02/Practitioner FINAL REPORT 021513.pdf

Nicodemus, B. (2009). Prosody and utterance boundaries in American Sign Language interpretation. Washington, DC: Gallaudet University Press.

Nicodemus, B, Swabey, L, \& Witter-Merithew, A. (2011). Presence and role transparency in healthcare interpreting: A pedagogical approach for developing effective practice. Rivista di Linguistica, 11(3), 69-83.

Olson, A., \& Swabey, L. (2013). Adaptive performance of American Sign Language interpreters who work in healthcare settings. (Poster 
presentation at the Association for Psychological Science Convention, Washington, DC, on May 25, 2013).

Pollard R., \& Barnett, S. (2009). Health-related vocabulary knowledge among deaf adults. Rehabilitation Psychology, 54(2), 182-185.

Reeves, D., \& Kokoruwe, B. (2005). Communication and communication support in primary care: A survey of deaf patients. Hearing, Balance and Communication, 3(2), 95-107.

Rubin, R. (2005). Adherence to pharmacologic therapy in patients with type 2 diabetes mellitus. American Journal of Medicine, 118, 27-34.

Sabaté, E. (2003). Adherence to long-term therapies: evidence for action. Geneva: World Health Organization.

Sandler, W. (1999). Prosody in two natural language modalities. Language and Speech, 42(2/3), 127-142.

Sandler, W., \& Lillo-Martin, D. (2006). Sign language and linguistic universals. New York: Cambridge University Press.

Scheier, D. (2009). Barriers to health care for people with hearing loss: A review of the literature. Journal of the New York State Nurses Association, Spring/Summer, 4-10.

Sencan, N. M., Wertheimer, A., \& Levine, C. B. (2011). What determines the duration of patient medication compliance in patients with chronic disease: Are we looking in the wrong place? Southern Medical Review, $4(2), 50-54$.

Shaffer, B. (2004). Information ordering and speaker subjectivity: Modality in ASL. Cognitive Linguistics, 15(2), 175-195.

Shattuck-Hufnagel, S., \& Turk, A. E. (1996). A prosody tutorial for investigators of auditory sentence processing. Journal of Psycholinguistic Research, 25, 193-247.

Starr, M., \& Graybill, P. (2012). Engaging the deaf community in research action. (Paper presented at Gallaudet University, Washington, DC, on October 15, 2012).

Steinberg, A., Barnett, S., Meador, H. E., Wiggins, E., \& Zazove, P. (2006). Health care system accessibility: Experiences and perceptions of deaf people. Journal of General Internal Medicine, 21(3), 260-266.

Steinberg, A. G., Wiggins, E. A., Barmada, C. H., \& Sullivan, V. J. (2002). Deaf women: Experiences and perceptions of healthcare system access. Journal of Women's Health, 11 (8), 729-741.

Swabey, L., Nicodemus, B., \& Moreland, C. (in press). An examination of medical interview questions translated in American Sign Language by deaf physicians and interpreters. In B. Nicodemus \& M. Metzger (Eds.) Investigations in healthcare interpreting. Washington, DC: Gallaudet University Press.

Swabey, L., \& Nicodemus, B. (2011). Bimodal bilingual interpreting in the U.S. healthcare system: A critical linguistic activity in need of investigation. In B. Nicodemus \& L. Swabey (Eds.), Advances in interpreting research: Inquiry in action (241-260). Amsterdam: John Benjamins.

Svarstad, B., Shireman, T., \& Sweeney, J. (2001). Using drug claims data to assess the relationship of medication adherence with hospitalization and costs. Psychiatric Services, 52, 805-811.

Ubido, J. (2002). Inequalities in access to healthcare faced by women who are deaf. Health \& Social Care in the Community, 10(4), 247-253.

Wilbur, R. B. (2000). Phonological and prosodic layering in American Sign Language. In K. Emmorey \& H. Lane (Eds.), The signs of language revisited (215-244). Mahwah, NJ: Erlbaum.

Witte, T. N., \& Kuzel, A. J. (2000). Elderly deaf patients' health care experiences. Journal of the American Board of Family Medicine, 13, $17-22$. 
Youdelman, M. K. (2008). The medical tongue: U.S. laws and policies on language access. Health Affairs, 27(2), 424-433.

Zazove P., Niemann L., Gorenflo, D., Carmack, C., Mehr, D., Coyne, J., \& Antonucci, T. (1993). The health status and health care utilization of deaf and hard-of-hearing persons. Archives of Family Medicine, 2(7), $745-752$. 
Appendix A

Medical Questions and Statements in the Order Presented to the Participants

1. Are you allergic to any medications?

2. Take this liquid medication four times a day-once after every meal and once before bedtime

3. Take one tablet twice a day with food or as needed for pain.

4. Take one teaspoon three times a day for 10 days. You should finish this medicine even if your symptoms disappear.

5. Are you sexually active?

6. Do you have a history of glaucoma in your family?

7. On a scale of 1 to 10 , how would you rate your pain right now?

8. Do you take any over-the-counter medications? 